\title{
$\kappa$-carrageenan induces the disruption of intestinal epithelial Caco-2 monolayers by promoting the interaction between intestinal epithelial cells and immune cells
}

\author{
HAI-YUE JIANG ${ }^{1}$, FENG WANG ${ }^{2}$, HAI-MIN CHEN ${ }^{1}$ and XIAO-JUN YAN ${ }^{1}$ \\ ${ }^{1}$ Key Laboratory of Applied Marine Biotechnology, Ministry of Education, Ningbo University, Ningbo, Zhejiang 315211; \\ ${ }^{2}$ Department of Clinical Laboratory, Ningbo Medical Center, Lihuili Hospital, Ningbo University, Ningbo, \\ Zhejiang 315041, P.R. China
}

Received June 6, 2013; Accepted October 7, 2013

DOI: $10.3892 / \mathrm{mmr} .2013 .1726$

\begin{abstract}
CGN}$ ) is an important food additive that has been demonstrated to induce colitis in animal models. In the present study, the effects of $\kappa-C G N$ were assessed using an in vitro co-culture system that contained intestinal epithelial Caco-2 cells and activated macrophage-like THP-1 cells. The results demonstrated that in single cultures of Caco-2 and THP-1 cells treated with $\kappa-\mathrm{CGN}$, the cytotoxicity and the secretion levels of IL-1 $\beta$, IL-6 and TNF- $\alpha$ were low. In the co-culture system, however, $\kappa-\mathrm{CGN}$ treatment resulted in apoptosis and reduced the transepithelial electrical resistance of the Caco- 2 cell monolayers. The secretion levels of TNF- $\alpha$, IL- $1 \beta$ and IL- 6 from the two cell types were increased significantly by $\kappa-\mathrm{CGN}$ treatment. Furthermore, pretreatment of the co-culture system with anti-TNF receptor 1 antibody suppressed the $\kappa$-CGN-induced apoptosis and attenuated the changes in the levels of IL- 6 and IL-1 $\beta$ in the Caco-2 monolayers. This study indicated that $\kappa-\mathrm{CGN}$-induced TNF- $\alpha$ secretion is the main contributor to cellular damage in Caco-2 monolayers exposed to $\kappa-\mathrm{CGN}$.
\end{abstract}

\section{Introduction}

Carrageenans (CGNs) are a group of large sulfated polysaccharides derived from red algae. The most common forms of CGNs are $\kappa, \iota$ and $\lambda(1)$. Of these, $\kappa-C G N$ is widely used as

Correspondence to: Professor Hai-Min Chen, Key Laboratory of Marine Biotechnology, Ministry of Education, Ningbo University, Caoguangbiao Technology Building, Fenghua Road, Post Box 71, Ningbo, Zhejiang 315211, P.R. China

E-mail: haiminch75@hotmail.com

Abbreviations: CGN, carrageenan; IBDs, inflammatory bowel diseases; PMA, phorbol myristrate acetate; TER, transepithelial electrical resistance

Key words: $\kappa$-carrageenan, colitis inflammation, co-culture, Caco-2 monolayers, TNF- $\alpha$ a thickening, gelling and stabilizing agent in various types of food products, such as desserts, sauces, milk, yogurt and meats (2).

The safety of food-grade CGN has been questioned for several decades. By reviewing animal studies on the effects of CGNs, Tobacman (3) identified that CGN may cause gastrointestinal pathology, including ulcerations and tumors of the gastrointestinal tract and, due to this fact, CGNs have been widely used to establish inflammation models. Therefore, Tobacman claimed that CGN may be harmful to the human gastrointestinal tract. However, these claims have been disputed by a number of international agents, including the U.S. Food and Drug Administration, the European Commission's Scientific Committee for Food and the Joint FAO/WHO Expert Committee on Food Additives. They evaluated Tobacman's study and concluded that 'there is no evidence of any adverse effects in humans from exposure to food-grade carrageenan' (4-8). Therefore, there is no absolute verdict on whether CGNs are safe for use by the food industry.

The present study also reviewed previous studies concerning the effects of CGNs in animal models and it was identified that the animals used were all healthy prior to the commencement of the studies. The conclusions from those studies were quite different from each other (1,3-10). These discrepancies may be due to the complexity of the various study systems. For example, in long-term assays, due to different methods of handling the animals, harmful bacteria may be increased in the gut and neutrophils may be transmigrated to the damaged tissues, resulting in varied immune responses to CGNs.

The mucosal surface of the gastrointestinal tract forms a barrier to separate the luminal contents from the effector immune cells underneath. Disruption of this barrier is critical in the initiation of inflammatory bowel diseases (IBDs) (11). It has become increasingly clear that intestinal epithelial cells are regulated by immune cells beneath the intestinal epithelial monolayer via soluble factors. Previous studies have suggested that intestinal intraepithelial lymphocytes or macrophages respond to stimulation by secreting cytokines $(12,13)$. Abnormal activation of these intestinal immune cells is likely to cause the overproduction of inflammatory cytokines, which may damage intestinal epithelial monolayers and disrupt 
subsequent mucosal inflammation (14). Previous analyses of the intestinal inflammatory effects of CGNs have been mainly performed using animal models. However, the detailed regulatory mechanism of CGN on the co-existent system of intestinal epithelial cells and macrophages has not been elucidated.

Therefore, in the present study, an in vitro model was established to evaluate the inflammatory effects of $\kappa-C G N$. A co-culture system comprising human intestinal epithelial-like Caco-2 cells and phorbol myristrate acetate (PMA)-stimulated THP-1 macrophage cells was used, based on the assumption that macrophages transmigrate to become situated underneath the intestinal epithelial cells. Cell-to-cell interactions between Caco-2 and THP-1 cells were also investigated using the co-culture system.

\section{Materials and methods}

Cell culture. Human colon adenocarcinoma Caco-2 cells [China Center for Type Culture Collection (CCTCC), Wuhan, China] at passages 30-60 were cultured in Dulbecco's modified Eagle's medium/Nutrient Mix F12 (Sigma-Aldrich, St. Louis, MO, USA) supplemented with $10 \%$ fetal bovine serum, $100 \mathrm{U} / \mathrm{ml}$ penicillin and $100 \mu \mathrm{g} / \mathrm{ml}$ streptomycin at $37^{\circ} \mathrm{C}$ with $5 \% \mathrm{CO}_{2}$ and $95 \%$ saturated atmospheric humidity. For the following assays, the seeding density of cells was $3-4 \times 10^{5}$ cells $/ \mathrm{ml}$. For co-culture, Caco-2 cells were cultured on $0.4-\mu \mathrm{m}$ semipermeable support membranes in 24-well cell culture inserts (Millicell culture cell inserts, Millicell-PCF; Millipore Ireland Ltd, Cork, Ireland). The Caco-2 cells were cultured for 15 days to obtain integrated cell monolayers with a transepithelial electrical resistance (TER) of $>200 \Omega . \mathrm{cm}^{2}$. THP-1 cells obtained from the CCTCC were maintained in RPMI-1640 medium supplemented with $10 \%$ fetal bovine serum, $2 \%$ glutamine, $100 \mathrm{U} / \mathrm{ml}$ penicillin and $100 \mu \mathrm{g} / \mathrm{ml}$ streptomycin at $37^{\circ} \mathrm{C}$ with $5 \% \mathrm{CO}_{2}$. The THP-1 cells used for co-culture were treated with $0.1 \mu \mathrm{g} / \mathrm{ml}$ PMA in 24-well plates to differentiate them into macrophage-like cells prior to being serum-starved for $12 \mathrm{~h}$.

Cell viability assays. 3-(4,5-Dimethylthiazol-2-yl)2,5-diphenyltetrazolium bromide (MTT) cytotoxicity assays were performed on 2-day and 15-day cultured Caco-2 cells and differentiated THP-1 cells that had been treated with $\kappa-\mathrm{CGN}$ to determine the cellular survival levels (15). Absorbance was measured at $492 \mathrm{~nm}$ with a Varioskan Flash (Thermo Fisher Scientific, Waltham, MA, USA). All experiments were repeated three times, and the data are presented as the percentages of the experimental viability of the treated cells compared with that of the control cells.

Co-culture. The semipermeable support membrane on which the Caco- 2 cells had been cultured for 15 days was placed on the macrophage-like THP-1 cells in the 24-well plates. Once the co-culture was started, various concentrations of $\kappa-C G N$ were administered to the upper Caco- 2 medium for a number of time periods.

Determination of cellular damage of Caco-2 monolayers. TER values were measured to assess the tight junction permeability and cellular damage of Caco- 2 cell monolayers. In the co-culture system, $\kappa-\mathrm{CGN}$ was applied to the upper Caco-2 medium. Following treatment, the cell monolayers were rinsed with phosphate-buffered saline (PBS) and TER values were measured with a Millicell ERS instrument (Millipore, Bedford, MA, USA). An empty millicell insert was used as a blank control. Incubation with PBS was set as the negative control. The TER value of 15-day cultured Caco- 2 cell monolayers prior to insertion into the 24-well plates was set as $0 \mathrm{~h}$.

Hematoxylin and eosin (H\&E) staining was performed to monitor the cellular damage to the Caco-2 monolayers. Briefly, following $\kappa-\mathrm{CGN}$ treatment, the membranes were washed with PBS and then fixed with $10 \%$ formaldehyde in PBS for $20 \mathrm{~min}$, prior to being stained with $H \& E$ for routine light microscopy. The H\&E stained areas were analyzed with Image-Pro Plus, version 5.1 (Media Cybernetics, Bethesda, MD, USA).

Annexin V-FITC/PI assay. Flow cytometry was performed to identify and quantify apoptotic and/or necrotic cells using the Annexin V-FITC/PI Apoptosis Detection kit (BD Biosciences Pharmingen, San Jose, CA, USA). The co-culture system was treated with various concentrations of $\kappa-\mathrm{CGN}$ or with the vehicle $\left(\mathrm{ddH}_{2} \mathrm{O}\right)$ for $24 \mathrm{~h}$, with or without pretreatment using $10 \mu \mathrm{g} / \mathrm{ml}$ anti-TNF receptor 1 (TNFR1) antibody (Santa Cruz Biotechnology, Inc., Santa Cruz, CA, USA). The Caco-2 cells were harvested by trypsinization, washed twice with PBS and resuspended in binding buffer. The resuspended cells were incubated with $5 \mu \mathrm{l}$ annexin V-FITC and $5 \mu \mathrm{l}$ PI for $15 \mathrm{~min}$ in the dark prior to being analyzed with a FITC/PI FACSCalibur flow cytometer (FACSCalibur; BD Biosciences Pharmingen). For each plot, annexin V-FITC-/PI- represents viable cells; annexin $\mathrm{V}-\mathrm{FITC}^{-} / \mathrm{PI}^{+}$represents necrotic cells; annexin $\mathrm{V}-\mathrm{FITC}^{+} / \mathrm{PI}^{-}$represents early apoptotic cells; and annexin $\mathrm{V}-\mathrm{FITC}^{+} / \mathrm{PI}^{+}$represents late apoptotic cells.

Cytokine measurements. Various concentrations of $\kappa-\mathrm{CGN}$ were administered to the upper medium of the co-culture system for $24 \mathrm{~h}$, with or without a pretreatment using $10 \mu \mathrm{g} / \mathrm{ml}$ recombinant human anti-TNFR1 antibody for $2 \mathrm{~h}$. The concentrations of cytokines (IL-8, TNF- $\alpha$, IL-6 and IL-1 $\beta$ ) in each collected supernatant were determined using IL-8, TNF- $\alpha$, IL-6 and IL-1 $\beta$ ELISA kits (R\&D Systems, Minneapolis, MN, USA) according to the manufacturer's instructions. The quantification was achieved by calibration with the standards. Cytokine secretions from single-cultured Caco-2 or THP-1 cells treated with $10 \mu \mathrm{g} / \mathrm{ml} \kappa-\mathrm{CGN}$ were also determined by ELISA assay.

Statistical analyses. All data are presented as the mean \pm standard deviation. Statistical comparisons between treated and control samples were performed using the Student's t-test. One-way analysis of variance followed by Duncan's multiple range test was used for analysis of differences among experimental groups (SPSS Software, version 16.0, SPSS, Inc., Chicago, IL, USA). A difference was considered to be statistically significant when $\mathrm{P}<0.05$.

\section{Results}

Effects of $\kappa-C G N$ on cell survival. The cytotoxic effects of $\kappa-C G N$ were determined for differentiated (15-day culture to 


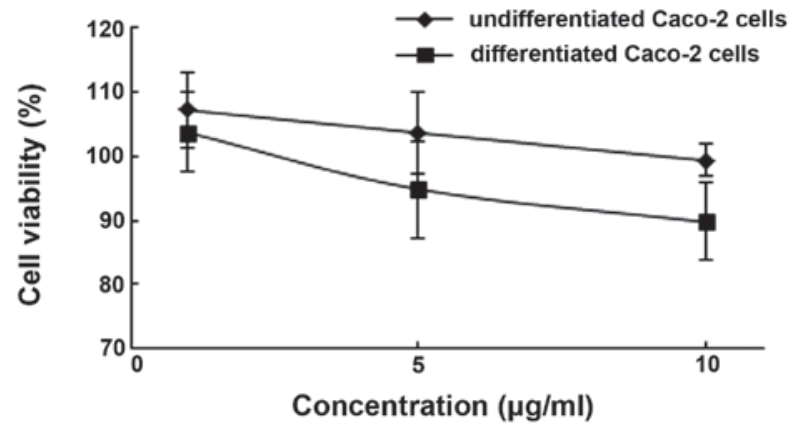

Figure 1. Cytotoxicity of $\kappa-\mathrm{CGN}$ in differentiated and undifferentiated Caco-2 cells. Two-day (undifferentiated) and 15-day (differentiated) cultured Caco-2 cells were treated with different concentrations of $\kappa-C G N$ for $24 \mathrm{~h}$ and cell viability was determined using an MTT assay. Cell survival $(100 \%)$ was assigned to the control without treatment and changes in cell viability relative to the control were calculated. The data are presented as the mean $\pm \mathrm{SD}(\mathrm{n}=3)$. $\kappa$-CGN, $\kappa$-carrageenan; MTT, 3-(4,5-dimethylthiazol-2-yl)2,5-diphenyltetrazolium bromide.

form monolayers) and undifferentiated (2-day culture) Caco-2 cells. The cells were treated with different concentrations of $\kappa-\mathrm{CGN}$ for $24 \mathrm{~h}$. As shown in Fig. 1, $\kappa-\mathrm{CGN}$ treatment resulted in a mild reduction in the survival of the differentiated and undifferentiated Caco-2 cells in a concentration-dependent manner. However, no evident cytotoxicity was observed. The differentiated Caco-2 cells were more sensitive to $\kappa-\mathrm{CGN}$ than the undifferentiated ones. For example, $10 \mu \mathrm{g} / \mathrm{ml} \kappa-\mathrm{CGN}$ treatment resulted in $10.26 \%$ inhibition of the survival of differentiated Caco-2 cells, but had little effect on the survival of the undifferentiated cells (Fig. 1). The effect of the incubation period on $\kappa-C G N$ cytotoxicity was also evaluated (Fig. 2). Incubation with $10 \mu \mathrm{g} / \mathrm{ml} \kappa$-CGN for $8 \mathrm{~h}$ had little effect on the survival of the differentiated Caco- 2 cells and the degree of inhibition was only $1.54 \%$. Following a $12-\mathrm{h}$ incubation, a more marked inhibitory effect was observed, which persisted for the duration of the 24-h experimental period. The effect of $\kappa$-CGN on differentiated THP-1 cells was also evaluated but no cytotoxic effects were detected. At $10 \mu \mathrm{g} / \mathrm{ml} \kappa-\mathrm{CGN}$, the viability of THP-1 cells was maintained at $109.45 \pm 20.49 \%$.

$\kappa-C G N$-induces damage to Caco-2 cell monolayers in the co-culture system. In the co-culture system, Caco-2 and THP-1 cells were not in contact with each other; thus, they interacted only via soluble factors secreted from each cell line.

Even without $\kappa-C G N$ treatment, co-culture with THP-1 cells caused slight damage to the Caco-2 cells, as demonstrated by the decreased TER value (Fig. 3) and H\&E staining (Fig. 4A). Following $\kappa-\mathrm{CGN}$ application, the damage increased significantly $(\mathrm{P}<0.01$; Fig. 3$)$. Even after only $24 \mathrm{~h}$ incubation with $1 \mu \mathrm{g} / \mathrm{ml}$, the TER value was decreased to the minimum recorded value, indicating that the monolayers were completely damaged.

The $\kappa-C G N$ treatment at $10 \mu \mathrm{g} / \mathrm{ml}$ was applied for $24 \mathrm{~h}$ to investigate the effects of incubation time on the integrity of monolayers and this was evaluated by monitoring their TER values. Longer periods of $\kappa-C G N$ treatment decreased the TER values, with the most marked changes occurring in the first $4 \mathrm{~h}$ (Fig. 5). Consistently, severe damage was observed following $4 \mathrm{~h}$ of treatment, with $85.42 \pm 8.74 \%$ of cells having been peeled off

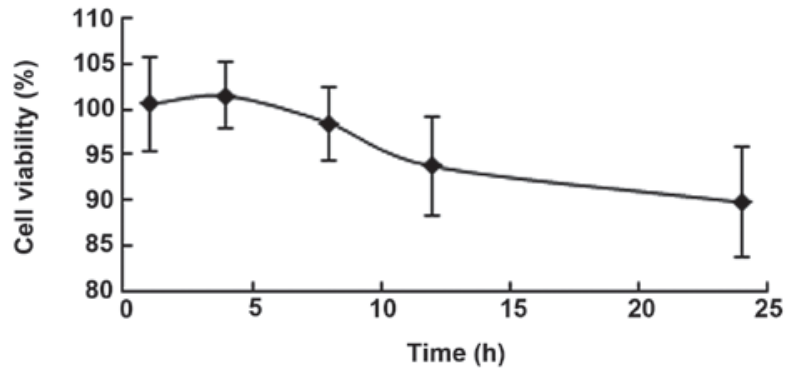

Figure 2. Effects of incubation time on the cytotoxicity of $\kappa$-CGN to differentiated Caco-2 cells. Fifteen-day (differentiated) cultured Caco-2 cells were treated with $10 \mu \mathrm{g} / \mathrm{ml} \kappa$-CGN for different time periods, and cell viability was determined using an MTT assay. The data are presented as means \pm SD $(n=3)$. $\kappa$-CGN, $\kappa$-carrageenan; MTT, 3-(4,5-dimethylthiazol-2-yl)-2,5-diphenyltetrazolium bromide.

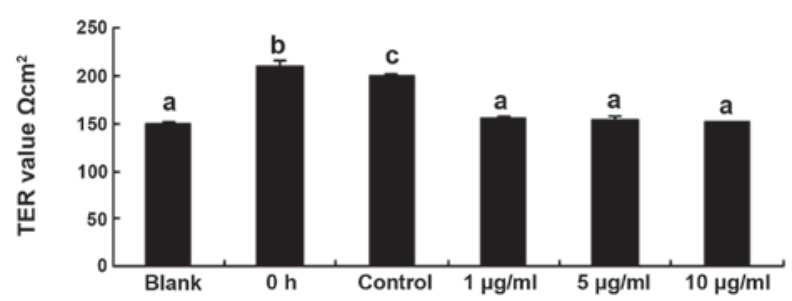

Figure 3. Effects of $\kappa-\mathrm{CGN}$ on the TER values of Caco-2 monolayers in the co-culture system. Caco-2 cells were co-cultured with differentiated THP-1 cells. $\kappa-\mathrm{CGN}$ was applied to the upper Caco- 2 medium for $24 \mathrm{~h}$ and the TER values of Caco- 2 cell monolayers were then determined. An empty millicell insert was used as a blank control. Incubation with PBS was set as a negative control. The TER value of 15-day cultured Caco- 2 cell monolayers prior to being inserted into 24-well plates was set as $0 \mathrm{~h}$. Each value is presented as the mean $\pm \mathrm{SD}(\mathrm{n}=3)$. Statistical significance was determined by one-way ANOVA followed by Duncan's multiple comparison test. Same lowercase letters in columns indicate there is no statistically significant difference $(\mathrm{P}<0.01)$, although the different letters indicate that they are significantly different from each other. TER, transepithelial electrical resistance; $\kappa$-CGN, $\kappa$-carrageenan; PBS, phosphate-buffered saline; ANOVA, analysis of variance.

and not stained by H\&E (Fig. 4C). Following $24 \mathrm{~h}$ of treatment with $5 \mu \mathrm{g} / \mathrm{ml} \kappa-\mathrm{CGN}, 83.04 \pm 6.28 \%$ of the Caco-2 monolayer was damaged (Fig. 4G). These results clearly demonstrate that $\kappa-C G N$ severely damaged the intestinal epithelial Caco-2 cell monolayers in the co-culture system.

Apoptosis and necrosis of Caco-2 cells are induced by $\kappa-C G N$. Annexin-V-FITC and PI staining was used to characterize the cellular damage to the Caco-2 monolayers. In this assay, the Caco- 2 cell monolayers in the co-culture system were incubated with various concentrations of $\kappa-C G N$ or with the vehicle for $24 \mathrm{~h}$. As shown in Fig. 6, the co-culture with THP-1 cells alone caused cellular damage, mainly necrosis and apoptosis, to the Caco-2 monolayers. The percentage of cells undergoing necrosis (annexin-V-FITC $/ \mathrm{PI}^{+}$quadrant) was $15.63 \%$, and that of cells undergoing apoptosis was $24.11 \%$ (Fig. 6A).

Treatment with $\kappa-C G N$ caused more significant levels of apoptosis in the Caco-2 monolayers. Specifically, the percentage of double positive cells (late stage of apoptosis) was increased from $12.41 \%$ to $38.23 \%$ when the cells were treated with $10 \mu \mathrm{g} / \mathrm{ml} \kappa-\mathrm{CGN}(\mathrm{P}<0.01)$, while the percentage of annexin-V-FITC ${ }^{+} / \mathrm{PI}^{-}$cells (early stage of apoptosis) was increased from $11.70 \%$ to $22.09 \%$ with $10 \mu \mathrm{g} / \mathrm{ml} \kappa-\mathrm{CGN}$ 

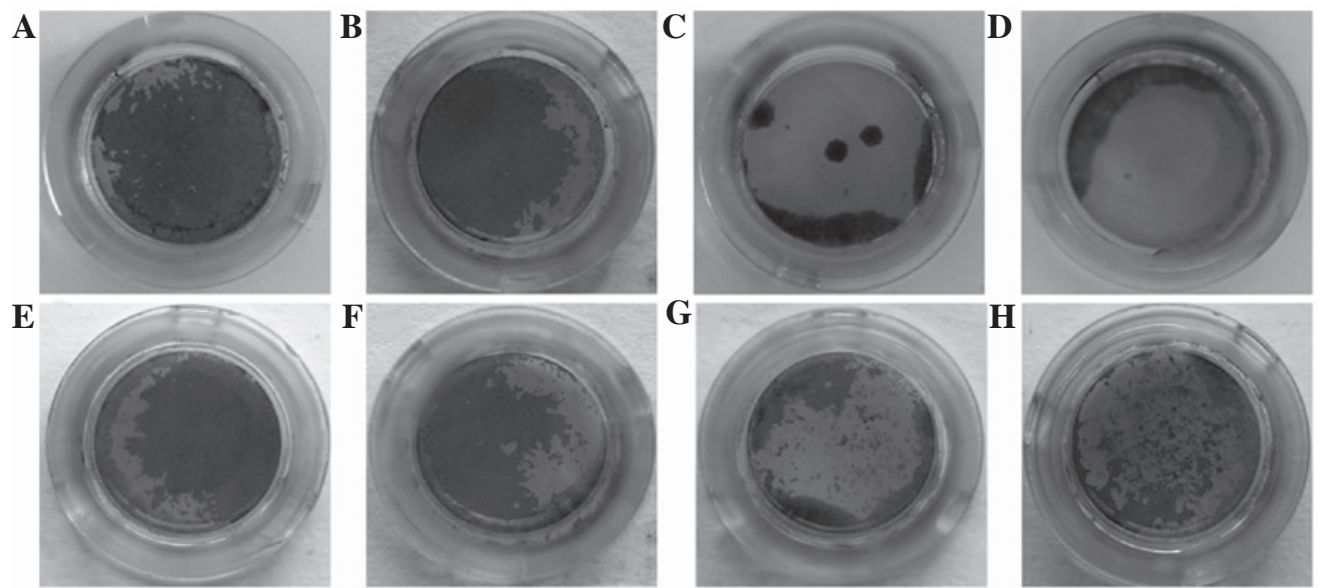

Figure 4. H\&E staining of Caco-2 monolayers treated with $\kappa$-CGN. In the co-culture system, $10 \mu \mathrm{g} / \mathrm{ml} \kappa$-CGN was added to the upper Caco-2 medium for (A) $0 \mathrm{~h},(\mathrm{~B}) 1 \mathrm{~h},(\mathrm{C}) 4 \mathrm{~h}$ or (D) $8 \mathrm{~h}$, or the upper Caco-2 medium was treated with (E) the vehicle, (F) $1 \mu \mathrm{g} / \mathrm{ml},(\mathrm{G}) 5 \mu \mathrm{g} / \mathrm{ml}$ or $(\mathrm{H}) 10 \mu \mathrm{g} / \mathrm{ml} \mathrm{\kappa}-\mathrm{CGN}$ for $24 \mathrm{~h}$. The membranes were washed with PBS and fixed in 10\% formaldehyde PBS for 20 min. The membranes were stained with H\&E for routine light microscopy. The $\mathrm{H} \& \mathrm{E}$ stained areas indicate the existence of cells on the membranes. H\&E, hematoxylin and eosin; $\kappa$-CGN, $\kappa$-carrageenan; PBS, phosphate-buffered saline.

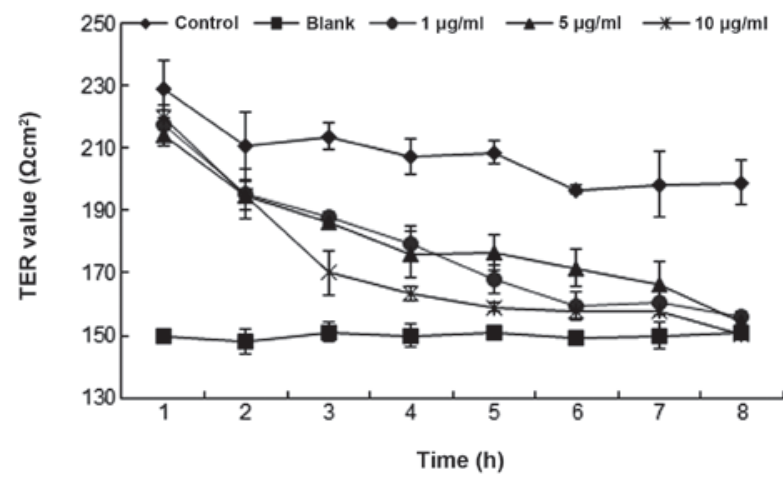

Figure 5. Effects of incubation time on the TER values of Caco-2 monolayers in the co-culture system treated with $\kappa$-CGN. Caco-2 cells were co-cultured with differentiated THP-1 cells. $\kappa$-CGN $(10 \mu \mathrm{g} / \mathrm{ml})$ was applied to the upper Caco-2 medium for different time periods, and the TER values of the Caco-2 cell monolayers were determined. Each value is presented as the mean $\pm \mathrm{SD}$ $(n=3)$. TER, transepithelial electrical resistance; $\kappa-C G N$, $\kappa$-carrageenan.

treatment. The necrosis, however, was actually reduced by $\kappa-C G N$ treatment in a concentration-dependent manner, indicating that $\kappa-C G N$ partially reduces the necrosis of Caco-2 cells when co-cultured with macrophage-like THP-1 cells.

Effects of $\mathrm{\kappa}-\mathrm{CGN}$ on the secretion of inflammatory cytokines from single-cultured cells. The secreted cytokines were tested to explore why co-culture rendered Caco-2 cells highly vulnerable to $\kappa$-CGN treatment. To exclude the contributory effects of $\kappa-C G N$ on the cells, the levels of secreted inflammatory cytokines in the single-cultured cells were measured first. As shown in Table I, no significant stimulatory effects of $\kappa$-CGN were observed for IL-1 $\beta$, IL- 6 and TNF- $\alpha$ in the differentiated or undifferentiated Caco-2 cells. The secretion of IL-8 was stimulated by $\mathrm{k-CGN}$ treatment, but the increased amount was too low to induce an effective inflammatory response. The levels of TNF- $\alpha$, IL- $1 \beta$ and IL- 8 were relatively high for THP-1 cells as they were treated with PMA and were significantly increased by $\kappa-C G N$ treatment $(\mathrm{P}<0.05)$.
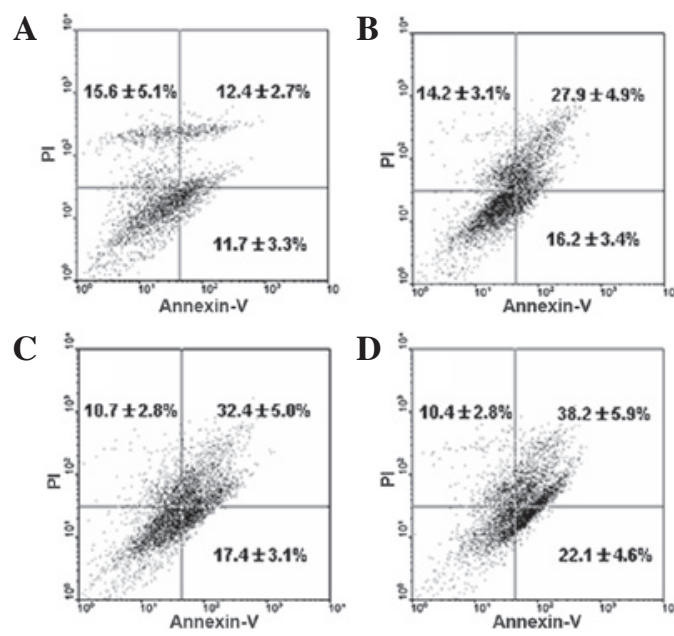

Figure 6. Percentage of apoptotic and/or necrotic cells in Caco-2 monolayers determined by an annexin V-FITC/PI binding assay. (A) Control, (B) $1 \mu \mathrm{g} / \mathrm{ml}$, (C) $5 \mu \mathrm{g} / \mathrm{ml}$ and (D) $10 \mu \mathrm{g} / \mathrm{ml} \kappa-C G N$. The different concentrations of $\kappa-C G N$ or the vehicle were administered to the upper medium of the co-culture system for $24 \mathrm{~h}$. The Caco-2 cells were harvested for flow cytometric analysis. For each plot, annexin V-FITC/PI- represents viable cells; annexin

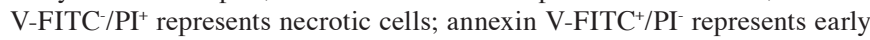
apoptotic cells; and annexin $\mathrm{V}-\mathrm{FITC}^{+} / \mathrm{PI}^{+}$represents late apoptotic cells Statistical significance was determined by one-way ANOVA followed by Duncan's multiple comparison test. Each value is presented as the mean \pm SD $(n=3)$. Differences in the number of late apoptotic cells between the control and $\kappa-C G N$ groups are statistically significant with $\mathrm{P}<0.01$ for all concentrations. $\kappa-\mathrm{CGN}$, $\kappa$-carrageenan; ANOVA, analysis of variance.

Secretion of inflammatory cytokines in the co-culture system. It has been demonstrated that co-culture of Caco-2 cells with THP-1 cells results in the secretion of TNF- $\alpha$ from THP- 1 cells, which causes cellular damage to the Caco-2 monolayers (16). In the present study, substantial increases in the secretion of TNF- $\alpha$ and also IL-1 $\beta$, IL- 6 and IL- 8 were detected in the medium of the Caco-2 cells. At the same time, the levels of these cytokines were also increased significantly in the underlayer medium of the THP-1 cells (Table II), indicating crosstalk between the Caco-2 and THP-1 cells via the secretion of these cytokines. Notably, in the Caco-2 cells without 
Table I. Inflammatory cytokines secreted from Caco-2 cells and THP-1 cells stimulated with $\kappa$-CGN.

\begin{tabular}{|c|c|c|c|c|}
\hline \multirow[b]{2}{*}{ Cytokine } & \multirow[b]{2}{*}{ Cells } & \multicolumn{3}{|c|}{ Cytokine level (pg/ml) } \\
\hline & & $\begin{array}{l}\text { Undifferentiated } \\
\text { Caco- } 2 \text { cells }\end{array}$ & $\begin{array}{l}\text { Differentiated } \\
\text { Caco-2 cells }\end{array}$ & $\begin{array}{l}\text { Differentiated } \\
\text { THP-1 cells }\end{array}$ \\
\hline TNF- $\alpha$ & $\begin{array}{l}\text { Control } \\
\kappa-\mathrm{CGN}\end{array}$ & $\begin{array}{l}\text { N. D. } \\
\text { N. D. }\end{array}$ & $\begin{array}{l}\text { N. D. } \\
\text { N. D. }\end{array}$ & $\begin{array}{l}109.0 \pm 9.4 \\
330.3 \pm 29.8^{\mathrm{a}}\end{array}$ \\
\hline IL-6 & $\begin{array}{l}\text { Control } \\
\kappa-\mathrm{CGN}\end{array}$ & $\begin{array}{l}1.4 \pm 0.2 \\
1.3 \pm 0.1\end{array}$ & $\begin{array}{l}4.1 \pm 0.5 \\
3.6 \pm 0.5\end{array}$ & $\begin{array}{l}4.4 \pm 1.0 \\
7.7 \pm 0.2\end{array}$ \\
\hline IL-1 $\beta$ & $\begin{array}{l}\text { Control } \\
\kappa-\mathrm{CGN}\end{array}$ & $\begin{array}{l}\text { N.D. } \\
1.4 \pm 0.2\end{array}$ & $\begin{array}{l}\text { N. D. } \\
\text { N.D. }\end{array}$ & $\begin{array}{l}109.6 \pm 11.0 \\
256.6 \pm 2.1^{\mathrm{a}}\end{array}$ \\
\hline IL-8 & $\begin{array}{l}\text { Control } \\
\kappa-\mathrm{CGN}\end{array}$ & $\begin{array}{l}109.7 \pm 18.9 \\
145.9 \pm 14.2\end{array}$ & $\begin{array}{l}269.1 \pm 19.8 \\
474.1 \pm 21.3^{\mathrm{a}}\end{array}$ & $\begin{array}{c}5936.4 \pm 122.9 \\
14156.5 \pm 108.6^{a}\end{array}$ \\
\hline
\end{tabular}

Statistical significance was determined by Student's t-test. ${ }^{\text {a }}<0.05$, compared with the control group value. Values are presented as the mean \pm SD $\kappa-C G N, \kappa$-carrageenan; N.D. indicates a value below the level of detection.

Table II. Effect of $\kappa$-CGN on inflammatory cytokine secretion from the two types of cells in the co-culture system.

\begin{tabular}{|c|c|c|c|c|c|c|}
\hline \multirow[b]{2}{*}{ Cytokines } & \multirow[b]{2}{*}{ Cell lines } & \multicolumn{5}{|c|}{ Cytokine level (pg/ml) } \\
\hline & & $\begin{array}{l}\text { Monoculture } \\
\text { control }\end{array}$ & $\begin{array}{l}\text { Co-culture } \\
\text { control }\end{array}$ & $\begin{array}{l}1 \mu \mathrm{g} / \mathrm{ml} \\
\kappa-\mathrm{CGN}\end{array}$ & $\begin{array}{l}5 \mu \mathrm{g} / \mathrm{ml} \\
\kappa-\mathrm{CGN}\end{array}$ & $\begin{array}{c}10 \mu \mathrm{g} / \mathrm{ml} \\
\kappa-\mathrm{CGN}\end{array}$ \\
\hline \multirow[t]{2}{*}{ TNF- $\alpha$} & Caco-2 & N. D. & $1225.3 \pm 23.1$ & $1480.3 \pm 30.7$ & $2215.7 \pm 40.1^{\mathrm{b}}$ & $2775.8 \pm 17.2^{\mathrm{c}}$ \\
\hline & THP-1 & $109.0 \pm 9.3$ & $3400.9 \pm 43.6^{a}$ & $4640.4 \pm 14.6^{b}$ & $5092.7 \pm 59.8^{c}$ & $5772.2 \pm 23.8^{c}$ \\
\hline \multirow[t]{2}{*}{ IL-6 } & Caco-2 & $4.1 \pm 0.5$ & $181.0 \pm 33.1$ & $210.1 \pm 30.2$ & $275.9 \pm 44.5$ & $321.25 \pm 18.29^{b}$ \\
\hline & THP-1 & $4.4 \pm 1.2$ & $404.5 \pm 41.8^{a}$ & $423.6 \pm 36.1$ & $460.3 \pm 40.1$ & $577.47 \pm 37.09^{b}$ \\
\hline \multirow[t]{2}{*}{$\mathrm{IL}-1 \beta$} & Caco-2 & N. D. & $298.5 \pm 47.0$ & $404.1 \pm 50.0$ & $496.0 \pm 57.3$ & $572.3 \pm 28.5^{\mathrm{b}}$ \\
\hline & THP-1 & $109.6 \pm 11.0$ & $714.6 \pm 23.1^{\mathrm{a}}$ & $756.8 \pm 20.6$ & $763.9 \pm 20.1$ & $941.8 \pm 36.9^{b}$ \\
\hline \multirow[t]{2}{*}{ IL-8 } & Caco-2 & $269.1 \pm 19.8$ & $33462.4 \pm 59.0^{\mathrm{a}}$ & $35332.2 \pm 30.7$ & $37842.7 \pm 40.1$ & $38904.5 \pm 87.2$ \\
\hline & THP-1 & $5936.4 \pm 104.5$ & $42763.0 \pm 106.4^{\mathrm{a}}$ & $43513.4 \pm 80.4$ & $44133.0 \pm 70.7$ & $44913.4 \pm 113.2$ \\
\hline
\end{tabular}

Statistical significance was determined by Student's t-test. ${ }^{\mathrm{a}} \mathrm{P}<0.01$, compared with the value of the control groups with cells cultured on their own. ${ }^{\mathrm{b}} \mathrm{P}<0.05$ and ${ }^{\mathrm{c}} \mathrm{P}<0.01$, compared with the value of the co-culture control groups. Values are presented as the mean $\pm \mathrm{SD} \kappa-\mathrm{CGN}$, $\kappa$-carrageenan; N.D. indicates a value below the level of detection.

к-CGN treatment, $24.11 \%$ apoptosis (including $12.41 \%$ late stage apoptosis and $11.70 \%$ early stage apoptosis) and $15.63 \%$ necrosis was observed (Fig. 6A).

When treated with $\kappa-\mathrm{CGN}$, the secretion of these four cytokines from the two cells lines was markedly increased in a concentration-dependent manner. Specifically, $\kappa-C G N$ treatment at $10 \mu \mathrm{g} / \mathrm{ml}$ resulted in 1.8, 1.9 and 2.3-fold higher secretion of IL- 6 , IL- $1 \beta$ and TNF- $\alpha$, respectively, in the upper layer supernatants than in the co-culture control. In the underlayer supernatants, this concentration of $\kappa-\mathrm{CGN}$ resulted in 1.9, 1.3 and 1.7-fold higher levels of secretion for these three cytokines. These results suggest that $\kappa-\mathrm{CGN}$ treatment promotes the communication between $\mathrm{Caco}-2$ and THP-1 cells, resulting in the augmented secretion of cytokines. The PMA-stimulated THP-1 cells alone generated high levels of IL-8; thus, no significant changes were observed in IL-8 secretion levels following $\kappa$-CGN treatment (Table II).

Effects of anti-TNFRl antibody against the $\kappa$-CGN-induced cellular damage of Caco-2 monolayers. $\kappa-\mathrm{CGN}$ treatment at $10 \mu \mathrm{g} / \mathrm{ml}$ induced $\sim 6,000 \mathrm{pg} / \mathrm{ml}$ of TNF- $\alpha$ secretion from the THP-1 cells in the co-culture system (Table II). Therefore, the Caco-2 monolayers in the co-culture system were incubated with $6,000 \mathrm{pg} / \mathrm{ml} \mathrm{TNF-} \alpha$ without $\kappa-\mathrm{CGN}$ treatment to explore the role of TNF- $\alpha$ in $\kappa-C G N$-induced apoptosis (Fig. 7). As shown in Fig. 7B, the exposure of Caco- 2 monolayers to TNF- $\alpha$ significantly increased the percentage of cells undergoing the early and late stages of apoptosis $(\mathrm{P}<0.01)$, in a similar manner to the $\kappa-C G N$ treatment at $10 \mu \mathrm{g} / \mathrm{ml}$. The TNFR1s were then blocked using an anti-TNFR1 antibody to confirm the role of TNF- $\alpha$, as TNFR1s are the primary type of receptor 

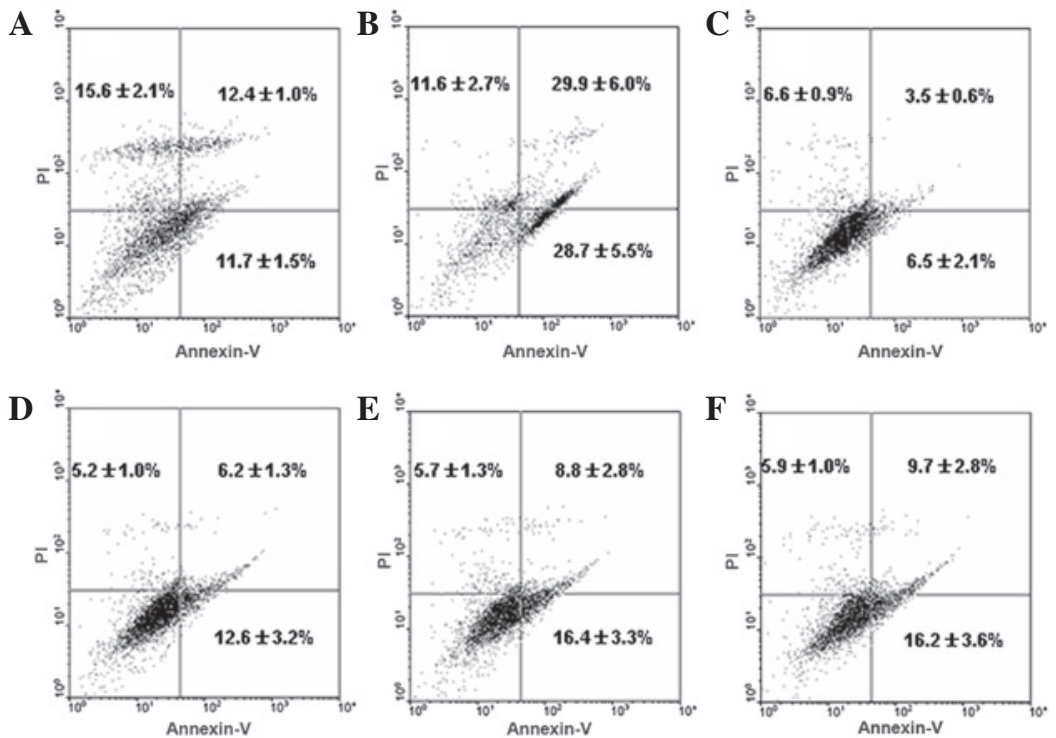

Figure 7. Role of TNF- $\alpha$ in the $\kappa$-CGN-induced apoptosis and necrosis of Caco-2 monolayers. The upper medium of the co-culture system was treated with (A) vehicle or (B) $6,000 \mathrm{pg} / \mathrm{ml} \mathrm{TNF}-\alpha$, or pretreated with $10 \mu \mathrm{g} / \mathrm{ml}$ anti-TNFR 1 antibody for $2 \mathrm{~h}$, prior to (C) the vehicle, (D) $1 \mu \mathrm{g} / \mathrm{ml}$, (E) $5 \mu \mathrm{g} / \mathrm{ml}$ or (F) $10 \mu \mathrm{g} / \mathrm{ml}$ k-CGN being applied for $24 \mathrm{~h}$. The percentage of cells undergoing apoptosis and/or necrosis was determined by an Annexin V-FITC/PI binding assay. Statistical significance was determined by one-way ANOVA followed by Duncan's multiple comparison test. Differences in the number of apoptotic cells (including early stage and late stage) between (A) and (B) are statistically significant with $\mathrm{P}<0.01$. Differences of apoptotic cells (including early stage and late stage) between (B) and (C-F) are statistically significant with P<0.01. $\kappa$-CGN, $\kappa$-carrageenan; TNFR 1, TNF receptor 1; ANOVA, analysis of variance.

mediating the TNF- $\alpha$-induced signaling pathways (17). As shown in Fig. 7C-F, the anti-TNFR1 antibody neutralized the THP-1-induced apoptosis and necrosis of Caco-2 cells $(\mathrm{P}<0.01)$. The proportion of apoptotic cells was reduced by $\sim 57 \%$ in the $10 \mu \mathrm{g} / \mathrm{ml} \mathrm{\kappa}$-CGN-treated group compared with the group of $10 \mu \mathrm{g} / \mathrm{ml} \kappa-C G N$ treated alone shown in Fig. 6D. This result strengthened the theory that TNF- $\alpha$ secreted by the THP-1 cells was the major factor that caused the damage associated with $\mathrm{k}-\mathrm{CGN}$ treatment.

Effects of anti-TNFR1 antibody on the secretion of $\mathrm{\kappa}-\mathrm{CGN}$-induced inflammatory cytokines. To evaluate the capability of TNF- $\alpha$ to act as a messenger in regulating the response of other inflammatory cytokines induced by $\kappa-C G N$ in the co-culture system, TNFR1s on the Caco-2 cells were blocked and the production of IL- 6 and IL- $1 \beta$ was examined. The production of IL- 6 was partially attenuated by the addition of the anti-TNFR1 antibody (Fig. 8A). This was particularly evident in the group treated with $10 \mu \mathrm{g} / \mathrm{ml}$ k-CGN, where the anti-TNFR1 antibody significantly suppressed IL-6 production $(\mathrm{P}<0.05)$ by $33.0 \%$. The anti-TNFR1 antibody demonstrated clear effects on IL-1 $\beta$ secretion $(\mathrm{P}<0.01)$. In the cells treated with 5 and $10 \mu \mathrm{g} / \mathrm{ml} \mathrm{\kappa}-\mathrm{CGN}$, increases in IL-1 $\beta$ production were partially blocked by the anti-TNFR1 antibody (Fig. 8B).

\section{Discussion}

The safety of using CGN as food additive has attracted a notable amount of attention. Using human colonic epithelial cell lines, Tobacman et al investigated the effects of CGN and reported the unexpected activation of innate immune responses through canonical and non-canonical NF-kB pathways (18-22). However, abnormalities in colonic epithelial cells are only part of the complex developmental process of IBDs. It has also
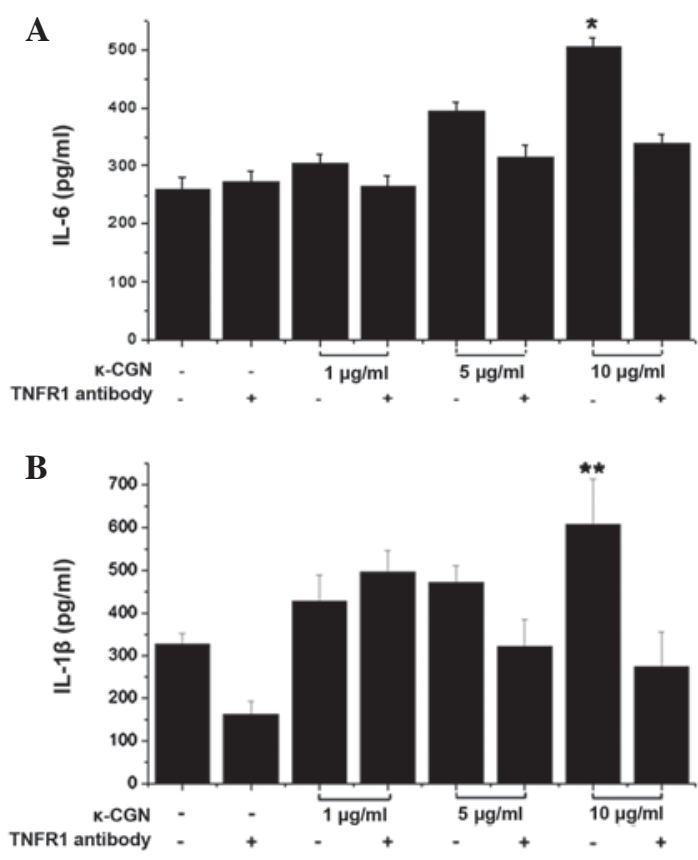

Figure 8. Effects of anti-TNFR1 antibody on the $\kappa-C G N$-induced secretion of inflammatory cytokines. The upper medium of the co-culture system was treated with different concentrations of $\kappa-\mathrm{CGN}$ for $24 \mathrm{~h}$, or pre-treated with $10 \mu \mathrm{g} / \mathrm{ml}$ anti-TNFR 1 antibody for $2 \mathrm{~h}$ prior to $\kappa-C G N$ being applied. The secretion of (A) IL-6 and (B) IL-1 $\beta$ from the upper medium was determined by an ELISA assay. Statistical differences between anti-TNFR 1 antibody pretreated groups and unpretreated groups were analyzed by Student's t-test. ${ }^{*} \mathrm{P}<0.05$ and ${ }^{* *} \mathrm{P}<0.01$. Each value is presented as the mean $\pm \mathrm{SD}(\mathrm{n}=3)$. $\kappa$-CGN, $\kappa$-carrageenan; TNFR 1, TNF receptor 1.

been demonstrated that intestinal epithelial cells interact with and are regulated by the immune cells beneath the intestinal epithelial monolayer via soluble factors (16). In IBD patients, intestinal epithelial cells and macrophages secrete large 
amounts of chemokines and pro-inflammatory cytokines (23). The molecular mechanisms beneath this, however, have not been clearly addressed. Previous studies have developed an artificial co-culture system to assess the interaction between intestinal epithelial cells and immune cells, in which intestinal epithelial cells are placed on the apical side and macrophage cells on the basolateral side in transwells $(16,23)$. In the present study, this in vitro model consisting of Caco-2 cells and PMA-activated macrophage-like THP-1 cells was used to investigate the effects of $\kappa-\mathrm{CGN}$ on gut inflammation.

CGNs have been demonstrated to induce the production of IL-8 (18), but the immune response was observed to be significantly weaker than the effects of lipopolysaccharide (LPS) on intestinal epithelial cells (24). Even studies using animal models have not clearly demonstrated whether CGNs harm the gastrointestinal tract or immune system. In the present study, it was hypothesized that carrageenans are potential conditional inflammatory agents. When the intestinal tract is 'unhealthy', CGNs may induce signal communication between immune and epithelial cells, resulting in damage to the intestinal tract. Using the co-culture system, the disruption of Caco-2 cell monolayers was observed, along with the increased secretion of TNF- $\alpha$, which is consistent with a previous study (16). Furthermore, treatment with anti-TNFR1 antibody blocked the increase in secretion of IL- 6 and IL-1 $\beta$ and partially attenuated the damage to the Caco-2 monolayers, demonstrating that TNF- $\alpha$ is the initial factor responsible for this damage. These results also indicated that the co-culture system employed in the present study was suitable for the assessment of the effects of $\kappa-C G N$ on the intestinal tract.

TNF- $\alpha$ is a special pleiotropic cytokine that mediates inflammation and cell death, including apoptosis and necrosis $(25,26)$. In the present study, increased secretion of TNF- $\alpha$ was observed following $\kappa-C G N$ treatment in the co-culture system, which is consistent with the increased apoptosis. This result is also consistent with the study by Ogata et al (27), which demonstrated that carrageenan induces TNF- $\alpha$ secretion in leukocytes. Notably, in the present study the levels of necrosis were reduced by $\kappa-\mathrm{CGN}$ treatment. Furthermore, the anti-TNFR1 antibody effectively neutralized $\kappa$-CGN-induced apoptosis, confirming the critical role of TNF- $\alpha$ in this process. This is contradictory to a previous study which demonstrated that exposure to CGN induced TNF- $\alpha$-stimulated inflammation but not apoptosis (22). This discrepancy may be explained by the differences in the cell lines and the carrageenan used in these two studies. However, in the previous study it was demonstrated that combined exposure to a CGN and TNF- $\alpha$ led to increased activation of the non-canonical pathway of $\mathrm{NF}-\kappa \mathrm{B}$ activation, and eventually to marked increases in IL-8 secretion (22). This is similar to the result observed in the present study, with the exception that the TNF- $\alpha$ used in the previous study was artificially added to the cell medium. In the co-culture system of the present study, TNF- $\alpha$ production from THP-1 cells was stimulated by $\kappa-\mathrm{CGN}$, which then acted on the Caco- 2 monolayers to increase the production of IL-8.

Significantly magnified secretion levels of inflammatory cytokines by $\kappa-\mathrm{CGN}$ were observed in the co-culture system used in the present study, which may induce an excessive inflammatory response (28). The significantly increased secretion of TNF- $\alpha$ may also modulate the production of IL-1 $\beta$ and IL-6 from immune cells to activate the inflammatory reaction or to regulate immune responsiveness. When the binding of TNF- $\alpha$ to its receptor was blocked, the production of IL- 6 and IL-1 $\beta$ from the Caco- 2 monolayers was attenuated.

In conclusion, in the present study an in vitro co-culture system utilizing Caco-2 cells and PMA-stimulated THP-1 cells was designed, and $\kappa-\mathrm{CGN}$ was demonstrated to promote the interactions between human colonic epithelial cells and immune cells through soluble factors, particularly TNF- $\alpha$. $\kappa-\mathrm{CGN}$ substantially induced the secretion of TNF- $\alpha$ from macrophage-like THP-1 cells, leading to a cascade of increased chemokines and pro-inflammatory cytokine production that caused the disruption of the Caco-2 monolayers, implying that $\kappa-\mathrm{CGN}$ as a food additive may be a safety concern.

\section{Acknowledgements}

This study was supported by grants from the National Science Foundation of Ningbo and Zhejiang (grant no. 2010A610028 and Y5100066), the Ningbo Marine Algae Biotechnology Team (grant no. 2011B81007), the K.C. Wong Magna Fund in Ningbo University and the Changjiang Scholars program.

\section{References}

1. Cohen SM and Ito N: A critical review of the toxicological effects of carrageenan and processed eucheuma seaweed on the gastrointestinal tract. Crit Rev Toxicol 32: 413-444, 2002.

2. Nicklin S and Miller K: Intestinal uptake and immunological effects of carrageenan - current concepts. Food Addit Contam 6: 425-436, 1989.

3. Tobacman JK: Review of harmful gastrointestinal effects of carrageenan in animal experiments. Environ Health Perspect 109: 983-994, 2001.

4. Grieg JB: Carrageenan (addendum). Safety evaluation of certain food additives. WHO Food Additives Series 42, no. 934. World Health Organization, Geneva, 1999.

5. Joint FAO/WHO Expert Committee on Food Additives (JECFA). Evaluation of certain food additives. WHO Technical Report Series 891. World Health Organization, Geneva, 2000.

6. JECFA: Evaluation of certain food additives specifications Addendum 9. Joint FAO/WHO expert committee on food additives, WHO Technical Report series. No. 891, 2001.

7. Scientific Committee on Food (SCF): Opinion of the scientific committee on food on carrageenan. European Commission, Brussels, 2003.

8. Benford DJ, Harrison RA, Strobel S, Schlatter J and Verger P: Carrageenan and processed Eucheuma seaweed (addendum). Safety evaluation of certain food additives and contaminants. WHO Food Additives Series 59. World Health Organization, Geneva, pp65-86, 2008.

9. Watson DB: Public health and carrageenan regulation: a review and analysis. J Appl Phycol 20: 505-513, 2007.

10. Weiner ML, Nuber D, Blakemore WR, Harriman JF and Cohen SM: A 90-day dietary study on kappa carrageenan with emphasis on the gastrointestinal tract. Food Chem Toxicol 45: 98-106, 2007.

11. Simpson S, Ash C, Pennisi E and Travis J: The gut: inside out. Science 307: 1895, 2005.

12. Cheroutre H: IELs: enforcing law and order in the court of the intestinal epithelium. Immunol Rev 206: 114-131, 2005.

13. Rodriguez P, Heyman M, Candalh C, Blaton MA and Bouchaud C: Tumour necrosis factor-alpha induces morphological and functional alterations of intestinal HT29 cl.19A cell monolayers. Cytokine 7: 441-448, 1995.

14. Shanahan F: Inflammatory bowel disease: immunodiagnostics, immunotherapeutics, and ecotherapeutics. Gastroenterology 120: 622-635, 2001 . 
15. Mosmann T: Rapid colorimetric assay for cellular growth and survival: application to proliferation and cytotoxicity assays. J Immunol Methods 65: 55-63, 1983.

16. Satsu H, Ishimoto Y, Nakano T, Mochizuki T, Iwanaga $T$ and Shimizu M: Induction by activated macrophage-like THP-1 cells of apoptotic and necrotic cell death in intestinal epithelial Caco-2 monolayers via tumor necrosis factor-alpha. Exp Cell Res 312: 3909-3919, 2006.

17. Pimentel-Muiños FX and Seed B: Regulated commitment of TNF receptor signaling: a molecular switch for death or activation. Immunity 11: 783-793, 1999.

18. Borthakur A, Bhattacharyya S, Dudeja PK and Tobacman JK: Carrageenan induces interleukin- 8 production through distinct Bcl10 pathway in normal human colonic epithelial cells. Am J Physiol Gastrointest Liver Physiol 292: G829-G838, 2007.

19. Bhattacharyya S, Borthakur A, Dudeja PK and Tobacman JK Carrageenan induces cell cycle arrest in human intestinal epithelial cells in vitro. J Nutr 138: 469-475, 2008.

20. Bhattacharyya S, Dudeja PK and Tobacman JK: Carrageenan-induced NFkappaB activation depends on distinct pathways mediated by reactive oxygen species and Hsp27 or by Bcl10. Biochim Biophys Acta 1780: 973-982, 2008.

21. Bhattacharyya S, Gill R, Chen M, Zhang F, Linhardt RJ, Dudeja PK and Tobacman JK: Toll-like receptor 4 mediates induction of the Bcl10-NFkappaB-interleukin-8 inflammatory pathway by carrageenan in human intestinal epithelial cells J Biol Chem 283: 10550-10558, 2008.
22. Bhattacharyya S, Dudeja PK and Tobacman JK: Tumor necrosis factor alpha-induced inflammation is increased but apoptosis is inhibited by common food additive carrageenan. J Biol Chem 285: 39511-39522, 2010.

23. Tanoue T, Nishitani Y, Kanazawa K, Hashimoto $\mathrm{T}$ and Mizuno M: In vitro model to estimate gut inflammation using co-cultured Caco-2 and RAW264.7 cells. Biochem Biophys Res Commun 374: 565-569, 2008

24. Bhattacharyya S, Borthakur A, Pant N, Dudeja PK and Tobacman JK: Bcl10 mediates LPS-induced activation of NF-kappaB and IL-8 in human intestinal epithelial cells. Am J Physiol Gastrointest Liver Physiol 293: G429-G437, 2007.

25. Schwabe RF and Brenner DA: Mechanisms of liver injury. I. TNF-alpha-induced liver injury: role of IKK, JNK, and ROS pathways. Am J Physiol Gastrointest Liver Physiol 290: G583-G589, 2006.

26. Gaur U and Aggarwal BB: Regulation of proliferation, survival and apoptosis by members of the TNF superfamily. Biochem Pharmacol 66: 1403-1408, 2003.

27. Ogata M, Matsui T, Kita T and Shigematsu A: Carrageenan primes leukocytes to enhance lipopolysaccharide-induced tumor necrosis factor alpha production. Infect Immun 67: 3284-3289, 1999.

28. Fraczek M, Sanocka D, Kamieniczna M and Kurpisz M Proinflammatory cytokines as an intermediate factor enhancing lipid sperm membrane peroxidation in in vitro conditions. J Androl 29: 85-92, 2008. 